\title{
Personal style and epistemic stance in classroom discussion
}

Sam Kirkham

University of Sheffield

School of English Literature, Language and Linguistics

University of Sheffield

Jessop West, 1 Upper Hanover Street

Sheffield S3 7RA

United Kingdom

Email: s.kirkham@sheffield.ac.uk

Slightly revised version to appear as:

Kirkham, Sam. 2011. Personal style and epistemic stance in classroom discussion. Language and Literature 20(3). 207-217.

Available at: http://lal.sagepub.com/content/20/3/201 


\title{
Personal style and epistemic stance in classroom discussion
}

\begin{abstract}
This article reports on an analysis of stance-taking in the university classroom, examining how students position themselves in relation to academic knowledge through the epistemic phrases I don't know and I think. Analysis of specific interactional moments reveals that the meaning of discourse forms is largely indeterminate without an understanding of the (1) the immediate discourse context; (2) the place of linguistic forms in an individual's stylistic repertoire; and (3) the ideologies and social categories that frame that stylistic repertoire. Differential knowledge distribution amongst the students places constraints on what certain individuals can do with particular linguistic forms and this analysis reveals how they utilise the same linguistic resources in different ways in order to do different identity work. Through detailed interactional analysis, I demonstrate that our ability to evaluate classroom discussion as a social practice relies upon our ability to situate that practice within an understanding of individual speakers' personal styles and the social ideologies that frame them.
\end{abstract}

\section{Keywords}

Style; stance; classroom discourse; gender; epistemic modality 


\section{Introduction}

This article reports on an investigation into how identity is constructed in the higher education classroom, demonstrating that an understanding of classroom discussion as a social practice requires us to situate that practice in terms of individual speakers' stylistic repertoires. I examine a situation where two students use similar linguistic forms in classroom discussion but possess differing levels of situation-relevant knowledge, which affects the ways in which those forms can be operationalised for stance-taking. In this way, these data suggest that the indeterminacy of linguistic forms is resolved by considering (i) the stance-taking value of that form in the specific interactional context; and (ii) the place of that form in an individual's broader stylistic repertoire.

It is widely recognised that the classroom is an important site for the negotiation of identity in interaction. In educational situations, multiple sources of knowledge, authority and identity are constantly active and constantly have to be negotiated and renegotiated across interaction. Often, participants have to simultaneously negotiate the demands of the institutional classroom and the demands of their peer group. At times, these demands may co-exist in harmony. Often, however, such demands clash and 
notions of legitimate participation undergo negotiation. An example of this can be found in Benwell and Stokoe (2002), where they analyse student resistance to academic identities in order to demonstrate how participants in talk negotiate notions of acceptable student behaviour. They find that, contrary to expectations of university discussion being tutor-controlled, student talk plays a significant role in negotiating and maintaining boundaries surrounding what counts as acceptable discussion in the classroom. In other research they further investigate the construction of gender (Stokoe, 1995, 1998), topicality (Stokoe, 2000) and knowledge (Benwell, 1999) in university classroom talk.

In a different line of inquiry, Wortham (2008) presents a detailed case-study of one student's identity in a middle-school US science classroom, where he tracks the progress of a student named Philip over a series of months. Wortham demonstrates how particular interactional events cause Philip's identification to shift over time from a smart student to relatively indeterminate to a low-status person. His analysis foregrounds how social identification is far from static and that academic and nonacademic resources are constantly available in the negotiation of classroom identity. What is particularly notable about Wortham's study is the recognition that the indeterminate meanings of language behaviour are not only resolved by contexts surrounding the specific interactional moment, but also by the practices and personality of the language user over time. 
All of the studies cited above make explicit the fact that, when people talk, they constantly make claims, encode attitudes and express evaluations towards the topic of their talk, the co-present participants, and any other social or conceptual entities invoked through talk. These attitudes and evaluations are here referred to under the banner of stance. Stance is often-used term across interactional linguistics, such as discursive psychology (Davies and Harré, 1990), conversation analysis (Local and Walker, 2008), linguistic anthropology (Kockelman, 2004), and interactional sociolinguistics (Kiesling 2001; Clift, 2006). Stance broadly refers to the attitudes, evaluations, and positionings that people take up in interaction relative to what they say and to whom they say it (cf. Johnstone, 2009: 30). However, stance can take multiple forms based on a combination of linguistic form and interactional effect. To this end, Kiesling (2009) classifies stance into epistemic and attitudinal dimensions, with epistemic stance referring to 'a person's expression of their relationship to their talk (their epistemic stance - e.g. how certain they are about their assertions)', whilst attitudinal stance concerns 'a person's expression of their relation to their interlocutors (their interpersonal stance - e.g. friendly or dominating' (Kielsing, 2009: 172). Of course, these two types of stance-taking are related and often co-occur. Kiesling gives the example of somebody who is being patronising (interpersonal) and is also very certain about what they are saying (epistemic), which concurrently makes an evaluation about the recipient's knowledge. While a recognition of locally-situated stance-taking is well explored in the 
literature, less common is an explicit recognition of how specific stances are connected to an individual speaker's broader stylistic repertoire. In resolving this matter, some scholars have proposed that, over the course of interactions, the communicative output of stances can build up and consolidate to index or make relevant more significant identifications. Du Bois (2002, cited in Bucholtz and Hall, 2005: 596) terms this accumulation of stance into a persona stance accretion. Repeated stances can act as the building blocks of interactional personae, drawn from an individual's stylistic repertoire. Kiesling (2009: 174-5) describes personal styles as 'repertoires of stances' and that 'identity and personal style are both ways of stereotyping habitual patterns of stancetaking', while Moore and Podesva (2009: 447) term styles 'clusters of features rather than singular and isolated forms divorced from other language'.

One of the benefits of approaching linguistic practice as stylistic practice is that it provides an embedding framework that can handle the indeterminacy of communication. A personal style can be conceived as 'a way of doing something' (Coupland, 2007: 1) that incorporates a range of social practices and, crucially, many of these practices may be indeterminate. Eckert (2001: 26) explains that such indeterminate forms acquire meaning when they jostle against the variety of other resources that together form a style. Thus, it would hold that the 'same' language form enacted by different individuals would not result in the same interactional effect, as its meaning is intrinsically tied to the entire interactional context in which it occurs, as well 
as that individual's stylistic repertoire. Coupland (2007) expands on this idea:

Linguistic and other semiotic features and styles need to be contextually primed before sociolinguistic indexing happens. This potential metaphorical transfer through which a linguistic feature comes to stand for or to mean something social has to be occasioned in discourse. The identificational value and impact of linguistic features depends on which discourse frame is in place. (Coupland, 2007: 112).

In this way, Coupland takes the view that the construction of stylistic meaning necessarily happens in situated interaction. This means that we not only need to consider the social situation in which features occur, but also the type of interactional work being done within that context, such as explaining, evaluating, arguing, or agreeing. This is taken up explicitly in the analysis in section 3.2, where occurrences of one discourse feature, I think, are coded in terms of the 'speech activity' in which they appear.

This article takes the perspective that stances are the building blocks of personal style and that this necessarily entails a bidirectional process of meaning making. An individual constructs particular stances that, over multiple interactions, may consolidate to form a more coherent and enduring interactional persona. At the same time, the 
interactional persona and stylistic repertoire of a particular individual feeds into every instance of stance-taking and infuses specific linguistic forms with social meaning, where they might otherwise be indeterminate with respect to their meaning or function. As such, our ability to evaluate how identity is constructed in educational settings relies upon situating the social practice of classroom discussion within an understanding of speakers' wider personal styles and the ideologies that frame them. In the analysis that follows, I examine how the situated use of discourse features enables academic knowledge to be negotiated and constructed in the higher education classroom. In particular, I focus on how students position themselves through the use of the epistemic phrases I don't know and I think. My account demonstrates that meanings are not associated directly with features, but that meaning is in part determined by the style in which those features are deployed, as well as by the specific interactional moment those features occur in. This suggests that dealing with the indeterminacy of linguistic forms can be achieved by treating an individual's linguistic performance as comprising a distinctive personal style from which resources are drawn in order to negotiate social relationships in interaction.

\section{Identity and interaction in the classroom}


The data reported on here are drawn from four months of fieldwork in which I observed and recorded the classroom discussion of an undergraduate English Literature seminar group. The course was a third-year module on American sports literature and included set texts from across the spectrum of literary study. As the module featured entirely sports-related content, the students' relationship to the texts was different from a usual literature module. In this case, knowledge about sports became a form of academic knowledge, in that one's knowledge about the basketball history was of equal use to one's knowledge of Romantic poetry in a seminar on Keats. As this article explores, knowledge of texts and their surrounding contexts is also an important resource for the negotiation of identity and interpersonal relations (e.g. Hade, 1991; Hall, 2008, 2009; Allington and Swann, 2009; Eriksson Barajas and Aronsson, 2009; Swann and Allington, 2009).

Recordings from six of the classes were transcribed in full, producing just under 56,000 words of classroom talk. The data were subjected to repeated listening and fragments were collated for interactional analysis. A series of features were also subject to quantitative analysis, which is reported on in more detail in Kirkham (2009). Quantitative measures are only referenced in the present study where appropriate.

Discourse features, such as epistemic phrases, are ideal for an analysis of stance because they are multifunctional and context-bound, but also retain a kernel of shared meaning across different contexts. For example, I don't know always carries with it 
some notion that the speaker lacks knowledge about something, even though such a phrase can actually be used to express varying knowledge states, as the analysis contained here shows.

Discourse features never work alone, however. In their analysis of tag questions, Moore and Podesva (2009: 449) state that 'syntax, phonology, and discourse work synergistically rather then independently of one another'. Other interactional analyses also demonstrate that stances are often communicated across stretches of talk, rather than being located in isolated features (e.g. Local \& Walker, 2008). As such, the procedure for the current data analysis was as follows. Tokens of I don't know and I think were identified from the transcribed corpus and extracted alongside their surrounding interactional context. The analysis then proceeded under the premise that an interactional outcome may be achieved by multiple linguistic features in interplay with each other. This is a similar to the ethnomethodological approach in that 'no order of detail can be dismissed a priori, as disorderly, accidental or irrelevant' (Heritage, 1984: 241), but this analysis does not commit to the other methodological principles of ethnomethodological conversation analysis, such as discussing social categories only when oriented by participants (Goodwin and Heritage, 1990: 295) and avoiding ethnographic (Haegeman, 1996) and quantitative (Schegloff, 1993) insights into the data (but see Wilkinson and Kitzinger, 2008 on social categories and participant orientation, and Moerman, 1988 on CA and ethnography). 
The other stance-taking devices considered in the interactional analysis include prosody and deixis. It has been well established that the prosodic and phonetic aspects of speech can have distinctive stance-taking functions (see contributions to CouperKuhlen and Selting, 1996; Couper-Kuhlen and Ford, 2004; Barth-Weingarten et al., 2010). At points in this analysis I report impressionistic auditory analyses of certain phonetic characteristics, such as intonation, vowel length, and voice quality (e.g. laughing voice quality). The analysis of deictic features, such as using pronouns in order to position knowledge sources, also features in interactional linguistics (Clift, 2006; Mondada, 2007) and is a well established research area in stylistics for its ability to provide insights into narrative perspective and speaker positioning (Gavins, 2007; Jeffries, 2008).

In the analysis that follows I present a case study of two of the eight students in the class, with the aim of highlighting the stylistic range in the community under study. In Kirkham (2009), I find that these two students generally occupy the statistical extremes in terms of their use of certain discourse markers and epistemic phrases. For example, they differ greatly in the frequency of use of one feature, I don't know, but share near-identical frequencies for another, I think. Both of these features are explored here. The individuals' relationships to relevant academic knowledge also represent the extreme ends of a continuum in the classroom. The two students are profiled briefly below. 
The first student, Tom, was a male American Studies student, born and raised in the UK. From the first seminar I observed, he immediately stood out as one of the more confident students. He spoke frequently, but in a relatively slow-paced and fairly quiet manner. He also produced more words than any other speaker in the class (average 1265 words per class). As I explore in the analysis, Tom regularly linked his discussion of the text or film under study to the sport's real-world context, particularly when talking about basketball. He had recently spent a year abroad studying in America and explained this in the first class, "prior to my year abroad I was interested in American sports like basketball but spending a year in America really developed my interest and knowledge of American sports and sports culture."

The other student, Elle, was the only non-British speaker in the class, being an exchange student from Canada in the penultimate year of her degree. She produced the lowest word count of the speakers who regularly attended class (average 448 words per class). She said she was interested in Canadian ice hockey, but often made claims such as "I don't follow any American sports teams" and "I took this class out of curiosity and with an interest in sports and literature I thought the combination would be fun." Although she evidently enjoyed sports, she made an effort to stress that she wasn't an expert, shown in the disclaimers present in her speech, such as "I don't know a lot like the rules or like the plays" and "I don't really read like the sports section". Elle was always very talkative and friendly with the other students and she and Tom appeared to 
be good friends.

\section{Epistemic stance in classroom discussion}

\subsection{I don't know}

In her corpus of Berwick-on-Tweed English, Pichler (2008) finds that realisations of $I$ don't know often take one of two syntactic configurations, namely 'bound' and 'unbound' forms. Bound forms are those that take a dependent complement, often a $W H$-word (e.g. "I don't know whether it's raining or not"), whereas unbound forms do not take a dependent element and usually form a single intonation unit (e.g. "she talks about it for, I don't know, about ten pages"). In addition, I don't know can also take referential or non-referential functions. Kärkkäinen (2003: 62) describes a referential tokens as an 'epistemic phrase' in that it conveys a degree of epistemic commitment with respect to the proposition to which it's attached. This is often the case with bound $I$ don't know, as well as with cases of unbound I don't know that form complete 'turn construction units' (Sacks et al., 1974) or 'phrasing units' (Selting, 2000: 477), such as single-phrase answers. On the other hand, non-referential I don't know generally acts more like a discourse marker, in that it has no explicit referent and often serves a more 
pragmatic function (Pichler, 2007: 177).

In the corpus, Elle, was the most frequent user of I don't know (3.57 tokens per 1000 words, $n=8)$, using it significantly more than the next highest speaker $[G(1)=5.4$, $p=.02]$. She was also the only speaker to use both bound and unbound forms of I don't know, whereas all of the other speakers only used one form categorically. In this section, I focus on Elle's use of bound and unbound I don't know and then contrast her bound tokens with those of Tom in order to demonstrate how different stances are taken up using similar resources.

\subsubsection{Unbound I don't know}

Most of the unbound tokens of I don't know in the corpus functioned similarly to discourse markers, in that they took no explicit referent. As my primary focus is epistemic phrases, these are not discussed here further (but see Kirkham 2009 for an analysis of these tokens). A number of Elle's unbound tokens were single-answer phrases, appearing as entire turn construction units or complete intonation phrases. An example of this usage is presented in fragment 1.

\section{Fragment 1}




\begin{tabular}{|c|c|c|}
\hline 1 & Tutor: & so what- you know one of the big cr- you \\
\hline 2 & & know big controversies that he states in terms \\
\hline 3 & & of black and white player[s ] \\
\hline 4 & Elle: & [he] says that a guy \\
\hline 5 & & is overrated \\
\hline 6 & Tutor: & which guy? \\
\hline 7 & Tom: & [Larry Bird]（(ALMOST INAUDIBLE)) \\
\hline 8 & All: & {$[\{$ laughter $\}]$} \\
\hline 9 & All: & [[ \{laughter $\}]]$ \\
\hline 10 & Elle: & {$[[$ I don't know $\{$ laughs $\}$} \\
\hline 11 & & he says a guy is overrated cause he's White]] = \\
\hline 12 & Hannah: & $=$ he says that Grant Hill's [overrated ] \\
\hline 13 & Tom: & [Larry Bird] \\
\hline 14 & Tutor: & [yeah he do]es also \\
\hline 15 & & say Grant Hill but you know it's like \\
\hline 16 & & what- why is reas- what is the reason that \\
\hline 17 & & Larry Bird is overrated? \\
\hline
\end{tabular}

In this extract the class are discussing basketball player Dennis Rodman's autobiography and the tutor asks a question about one of the claims that Rodman makes 
about White basketball players. Elle initially answers, "he says that a guy is overrated". Immediately after, the tutor asks "which guy?" with a lengthened vowel and laughing voice quality on 'guy'. Listening to the audio recordings, the teacher's prosody strongly suggests that this 'guy' is somebody whom Elle should know (it's later confirmed Larry Bird, one of the most famous basketball players of all time). The class immediately laugh and Elle says "I don't know" in overlap. This token is an epistemic phrase and it locates an expressed lack of knowledge in Elle's deictic centre. The pitch of this phrase falls at consistent intervals over the three syllables of the intonation unit and ends with a lengthened vowel on 'know'. Her prosody impressionistically infers a self-conscious lack of knowledge, taking up an explicitly unknowledgeable stance. She attempts to preserve interactional face on line 11 by repeating her initial talk ("he says a guy is overated") with laughing voice quality and then by further elaboration ("cause he's White"). Overall, Elle takes up an explicitly unknowledgeable stance with respect to sporting knowledge. This stance is oriented to by herself (the pitch declination on $I$ don't know), her classmates (their laughter), and the tutor (emphatic prosody on "which guy?"). Meanwhile, Tom has produced the correct answer twice in overlap, which is tacitly acknowledged by the tutor in lines 16-17.

\subsubsection{Bound I don't know}


All examples of bound I don't know presented here feature it attached to a clause about sporting knowledge. In the extract below, Elle explains why she enjoyed the non-fiction text The Girls of Summer: The U.S. Women's Soccer Team and How It Changed The World (Longman, 2001) over the other texts studied on the course.

\section{Fragment 2}

1 Elle: I really liked it [yeah] it-

2 Tutor: $\quad[\mathrm{mm}]$

3 Elle: well I think (.) cause I player soccer back home

4 Tutor: $\quad \mathrm{mm}$

5 Elle: and I found with the- a lot of the other books

$6 \quad$ um (.) I'm not (.) I'm not very-

7 I don't know a lot like the rules or like the

$8 \quad$ [plays] and so I can't (.)

9 Tutor: $\quad[\mathrm{mm}]$

10 Elle: I can't picture it or understand it as well as I

11 could this one

12 Tutor: okay 
Elle explains that she likes the particular book under study because she doesn't know a lot of the rules or structures of the sports featured in the other books. In doing so, she uses bound I don't know as an epistemic marker, formulating an explicitly unknowledgeable stance towards sporting facts. This token is also surrounded by false starts ("so I can't (.)"), pronoun/negation adverb constructions (“I'm not", "I’m not very"), and filled pauses (“um"), contributing to the uncertain or unassertive stance.

Like Elle, Tom also uses I don't know to comment on a lack of knowledge about sports, but the effect of this is very different. Extract 3 details him talking about Dennis Rodman's (1997) autobiography Bad as I Wanna Be.

\section{Fragment 3}

1 Tom: I kinda thought that (.)

I don't know loads about basketball but I (.)

obviously since like the (.) eighties and the

inter nineties it's kindaso much a part of the game it's kind of more 
Tom's bound I don't know in line 2 forms the basis for a disclaimer: "I don't know loads about basketball but". In doing so, he signals that his upcoming talk will probably include some assessments about basketball, but he propositionally infers that these should be approached with caution (Overstreet and Yule, 2001: 49). While the disclaimer softens face threats from any potential corrections, it soon becomes clear that his knowledge of basketball is fairly extensive, with comparisons between basketball in "the eighties and inter-nineties" and "the seventies and sixties", as well as the epistemic strength that the modal adverb 'obviously' affords. In this way, Tom's disclaimer mitigates his knowledge display, perhaps softening any student perceptions of him as too geeky or too knowledgeable (cf. Stokoe, 2000: 196-8) and potentially acting as face-preserving, in case of any of his claims are critically evaluated by other participants, such as the tutor.

This brief discussion shows that Elle is the most frequent user of I don't know and that her unbound tokens often take the form of single-answer epistemic phrases through which she explicitly denies possessing situation-relevant knowledge. Further consideration of her use of bound I don't know similarly reveals differences from the 
other speakers, such as Tom, who used the form to mitigate an extensive situationrelevant knowledge display. In contrast, Elle communicates an explicitly unknowledgeable stance towards sports and in doing so adopts an explicitly 'nonexpert' persona relative to sporting knowledge. This comparative analysis demonstrates how attending to the discourse context of a feature is crucial in determining the contextspecific meaning of a particular linguistic form and how academic knowledge surrounding a text (in this case sports knowledge) can be drawn upon to negotiate interpersonal relations in conversational interaction.

\subsection{I think}

If I don't know propositionally amounts to claiming a lack of knowledge, the epistemic status of I think is less clear. I think has been variously referred to as a modal particle (Aijmer, 1997), a discourse marker (Fung and Carter, 2007), and a 'prototypical' epistemic phrase (Kärkkäinen, 2003: 99). Grounded in the participant's use of the phrase in the extracts presented here, I adopt Kärkkäinen's designation of I think as an epistemic phrase, in that it is often used to index degrees of certainty, commitment, and epistemic stance towards the clause to which it is attached. Kärkkäinen explains: 
We can clearly state of I think that it indexes an utterance to the speaker and generally looks forward in discourse. It is speaker-oriented in its indexical meaning, in that it (still) explicitly refers to the speaker and personalizes an utterance-action, whether it thereby then only acts as a starting-point or does some more consequential interactional work. (Kärkkäinen, 2003: 174).

Gavins (2007: 111) claims that the deictic structure of an epistemic modal 'normally reflects the perspective of the person responsible for the thought process being described'. As such, this feature is highly significant in an investigation of stance as $I$ think may be used to convey the perspective, opinions, and epistemic commitment of its speaker.

\subsubsection{Quantitative analysis}

Tom and Elle were the most frequent users of this form, with near identical frequencies of $5.22(n=33$, Tom) and $5.36(n=12$, Elle) tokens per 1000 words respectively. While they were the most frequent users of I think in the class, the mean of their usage was not statistically significant against the next highest speaker, Hannah $[G(1)=0.96, p=.33]$. 
However, what's interesting in this particular case is the fact that Tom and Elle use $I$ think with such similar frequencies, but appear to have been constructing very different stances when using I don't know.

Tom and Elle's use of I think was first coded for syntactic position. The results appear in Table 1. All but one of Tom's tokens were clause-initial, while $75 \%$ of Elle's were initial. Holmes (1990: 187) claims that final-position I think is likely to be 'tentative', whereas initial-position is more likely to be 'deliberative'. Ariel (2009: 21) finds that medial $I$ think takes on a function similar to that of an epistemic modal adverb. Although based on low token counts, these frequencies suggest that almost all of Tom's I think utterances are broadly deliberative, whereas only $75 \%$ of Elle's are the same, the rest being tentative or adverbial in nature. Due to the majority of tokens appearing in initial position, I focus only on these for the rest of this section, but note that Elle is likely to be using I think for more tentative or adverbial ends in her use of medial and final forms.

Table 1: Syntactic position of Tom's and Elle's use of I think

\begin{tabular}{llll}
\hline Speaker & Initial & Medial & Final \\
\hline Tom & $96.97 \%$ & - & $3.03 \%$
\end{tabular}




$$
\text { Elle } \quad 75.00 \% \quad 16.67 \% \quad 8.33 \%
$$

(9) (2) (1)

Syntactic configuration only provides part of the picture however. Further insights were revealed when occurrences of I think were coded for the 'discourse frame' (Coupland, 2007: 112) or 'speech activity' (Kiesling, 2009: 180) in which they occurred (see Table 2).

Table 2: Tom's and Elle's use of I think in terms of speech activity

\begin{tabular}{lll}
\hline Speech activity & Tom & Elle \\
\hline False-start/self-interruption & $30.30 \%$ & $41.67 \%$ \\
& $(10)$ & $(5)$ \\
Personal narrative & $15.15 \%$ & $8.33 \%$ \\
& $(5)$ & $(1)$ \\
Evaluation: text & $15.15 \%$ & $25.00 \%$ \\
& $(5)$ & $(3)$ \\
Evaluation: character & $12.12 \%$ & $16.67 \%$ \\
& $(4)$ & $(2)$
\end{tabular}




\begin{tabular}{lll} 
Recounting textual narrative & $6.06 \%$ & $8.33 \%$ \\
Evaluation: outgroup claim & $(2)$ & $(1)$ \\
& $6.06 \%$ & - \\
Evaluation: co-participant claim & $9.09 \%$ & - \\
& $(3)$ & \\
Expressing sporting facts & $6.06 \%$ & - \\
\hline
\end{tabular}

On the whole, Tom and Elle's usage is reasonably similar based on speech activity. After I think's occurrence in false-starts and self-interruptions, both speakers used it most frequently in evaluating events or narratives in the texts under study. There were also three speech activities in which only Tom's tokens of I think occur, which pooled together represent $21.2 \%$ of his total use of the phrase. This suggests that Tom is using $I$ think to engage in activities that Elle isn't and that his use of I think here may be serving a different function. As such, I begin by considering the speech activities in which both Tom and Elle use I think, before analysing those where only Tom's tokens feature.

\subsubsection{Comparable speech activities}


After 'false-start/self-interruption' contexts, the majority of Tom's $(15.25 \%, n=5)$ and Elle's $(25 \%, \mathrm{n}=3)$ I think tokens occur in the 'evaluation: text' speech activity. I generally coded this category as utterances that used I think to modify an evaluation of the book or film under study, either in terms of the whole text or of a specific narrative event. Fragment 4 features all three instances of Elle's 'evaluation: text' tokens, in which she discusses Hoop Dreams (James, 1994), a non-fiction documentary about two school-age aspiring basketball players.

\section{Fragment 4}

1 Elle: I think the fact that there is a camera in the schools and the school is being watched and like (.) other people were (.) like involved in it

4 (.) they were able to get a publicity that they wouldn't have been able to get otherwise (.) which is why I think they might have kept the boys on (.) their school team (.) as well which also helped them (.)

9 Tutor: $\quad[\mathrm{mm}]$

10 Elle: [get ] into schools and stuff so I think the fact 
that there was like a camera (.) involved in (.) in the process and peoplelike it's all about like the gaze and like Foucault's (.) you know (1.3) like altering your behaviour (1.2)

16 Tutor: your behaviour [because there's a camera]

17 Elle: [your be- your behaviour] because there's a camera yeah

19 Tutor: yeah (.) okay

Elle's first token hypothesises some potential consequences of the school being the subject of the documentary under study. She uses I think directly before the NP + thatclause construction in order to posit a 'fact' ("there is a camera in the schools"), before connecting this to a causal explanation: "they were able to get publicity". Her second token also clusters around notions of causality (line 6), appearing clause-medially in order to post-modify the "which is why" causal conjunction. This utterance is already modified by the epistemic modal verb 'might', so the clustering of the clause-medial adverbial I think (Ariel, 2009: 21) around other modals contributes to a slightly weakened epistemic stance (Kärkkäinen, 2003: 128). All of Elle's tokens in this extract 
modify utterances concerning causality in that she evaluates the likely effects of the documentary's narrative for its non-fictional protagonists. On the one hand, Elle's I think has an assertive function. Her claims (e.g. that a documentary filmed in the school results in publicity) are relatively incontestable, so she has nothing to lose by epistemically marking her propositions in this way. Indeed, this may be one way of presenting relatively incontestable claims as her own opinions, positioning herself as the source of legitimate knowledge. On the other hand, the co-occurrence of other epistemic modals (e.g. "maybe") and clause-medial I think, in addition to her use of epistemic phrases (e.g. I don't know) in other contexts, infers that Elle's I think possibly contributes towards the construction of a more 'tentative' stance, alongside the aforementioned 'assertive' stance.

Tom's use of 'text: evaluation' I think works in different ways. The extract below comes after another classmate, Matt, has just criticised Bad as I Wanna Be, basketball player Dennis Rodman's autobiography. Matt claims that Rodman “deliberately sets out to aggravate to show he's the individual, he's trying to prove to everyone, I'm an individual". In reply, Tom states:

\section{Fragment 5}

1 Tom: I think the book makes you think that more than the reality of what actually happens 
I think the book is kind of

its purpose is to make you think like that it's to make you think oh he's (.) he's such a rebel or he's being like really (.) he's being really difficult on purpose to show how (.) how much of an individual he is and I was thinking (.) when I finished it I thought that (.) it's very easy to get carried away with (.) the book kind of make- make- (.) it's trying to make you think in a certain way and it's really easy to do that (.) to kind of think (.) to be kind of influenced by how it's written and what he says about certain things you just think oh he's an idiot he's doing this he's doing that but a lot of it (.) I think a lot of it's kind of you have to take it with a pinch of salt

The first token of I think (line 1) features Tom's assessment of Matt's criticism and he speculates on the book's effect on the reader. He does so by using the indefinite second- 
person pronoun you to generalise his claim out to an equally indefinite number of readers (Wales, 1996: 78), before contrasting this interpretation with "the reality of what actually happens" (line 2). Tom's adverb of actuality (“actually") acts as a strong epistemic marker, grounded in Tom's observations of "reality", and infers that Tom indeed knows "what actually happens" in basketball. This type of construction also features in lines 16-19, where Tom posits an interpretation of the text ("you just think oh he's an idiot"), before contrasting this with his opinion ("I think a lot of it's kind of, you have to take it with a pinch of salt"). Both the existing interpretation ("you just think") and the recommended interpretation ("you have to") similarly feature indefinite second-person pronouns.

In comparison, Elle evaluates the causal consequences of events for the people in the documentary, whereas Tom expresses a critical stance towards both what the book "makes you think" and how a reader should instead interpret the book.

Subsequently, these evaluations vary significantly in how contestable they are, with Tom's claims about how people ought to interpret texts being much more susceptible to challenges than Elle's. As such, Tom projects an 'authoritative' stance in offering such evaluations, while his reference to "reality" and extra-textual sporting knowledge perhaps transforms this into a near 'sports expert' persona. Alongside the other features of his style (e.g. near absence of you know, using I don't know to mitigate displays of expert knowledge), Tom constructs an identifiably 'knowledgeable' and 'expert' 
persona, which accrues meaning by the fact that the other students do not engage in similar displays of knowledge.

\subsubsection{Tom-only speech activities}

While Tom and Elle's shared speech activities contain distinct uses of I think, there are also three speech activities in which only Tom's tokens occur. One of these is 'evaluation: outgroup claim'. Prior to the passage below, the students have been discussing the Hoop Dreams documentary. In particular, they have been focusing on the film's overwhelming visual emphasis on the black players' bodies.

\section{Fragment 6}

1 Tutor: so it reinforces stereotypes and reinforces

2 Adam: [yeah it doesn't do (xx)]

3 Tutor: [a narrative ] a narrative of black

4 athleticism $=$

5 Adam: =yeah

6 Tutor: as juxtaposed to (.) alternative stories (.)

7 Adam: $\quad$ yeah $=$ 


$\begin{array}{ll}8 \text { Tutor: } & \text { (1.5) } \\ 9 & \text { I- I'd kind of agree with that (.) in a way cause } \\ 10 & \text { Tom: } \\ 11 & \text { as like a completely black sport is- is (.) kind of } \\ 12 & \text { wrong and the way (.) things like this present } \\ 13 & \text { it as kind of like (.) the only people (.) the only } \\ 14 & \text { people who- who play it are kind of from the inner } \\ 15 & \text { city and (.) and come out of hardship } \\ 16 & \text { and stuff it's kind of like (.) like the bit you } \\ 17 & \text { showed with Spike Lee and like a lot of the } \\ 18 & \text { kids in that camp were white and it's like } \\ 19 & \text { sometimes I was sat there thinking } \\ 20 & \end{array}$

In this instance, the 'outgroup claim' is 'the kind of image of basketball as like a completely black sport". This refers to what Tom perceives as a widely-held societal belief that basketball is primarily played and appreciated by black people. As was the case with the 'text: evaluation' examples, Tom positions such belief as conflicting with what he sees as the reality of the situation. Although his claim is hedged by "in a way", "the kind of image" and "kind of wrong" (lines 10-13), he directly locates epistemic 
commitment for this claim in his own deictic centre. By once again challenging received wisdom, Tom critically evaluates an outgroup perspective and positions himself as possessing the correct knowledge, as opposed to the misinformation that's being evaluated.

In the ways demonstrated here, Tom builds up a series of strongly evaluative stances, which consolidate into a distinctly 'sports expert' persona. This contrasts with Elle's attempts to explicitly mark her lack situation-relevant knowledge about sports. By considering how both individuals use different linguistic forms, and the different social practices they engage in during classroom discussion, individual stances can be contextualised in terms of the individuals' broader personal styles. In turn, this affords richer interpretations of social and linguistic behaviour as it occurs in interactional speech and resolves some of the indeterminacy in language behaviour.

\section{Discussion and conclusion}

This article presents an account of language use in a university classroom, demonstrating that our ability to evaluate academic discussion as a social practice relies upon situating that practice within an understanding of speakers' wider personal styles. The analysis reveals that individuals engaged in classroom discussion may draw upon 
similar resources, such as I think and I don't know, but that these forms are ultimately indeterminate without a consideration of (i) the specific interactional context in which they take place; and (ii) the place of those forms in an individual's stylistic repertoire.

By taking token frequency as a starting point, it becomes apparent that using a form in the same frequency does not necessarily lead to similar uses of the form. The analysis of I don't know shows how, what at first appears to be a straightforward disclaimer of knowledge, is highly context-dependent and can take on different functions when combined with different discourse content. Tom and Elle both used $I$ think with similar frequency, but the stances projected via this phrase also differ considerably. In the 'evaluation: text' speech activity Elle generally uses I think in order to evaluate the potential causes and consequences of narrative events, while Tom evaluates how the text ought to be interpreted. Elle constructs a combination of assertive and tentative stances through I think's co-occurrence with other modals, while Tom takes up a knowledgeable and authoritative stance that accretes into his 'sports expert' persona. Tom also participates in certain speech activities in which Elle doesn't, such as evaluating outgroup claims. One outcome of this is that linguistic features are often multifunctional and highly context-depend. While forms such as I don't know and I think always carry some semantic content on a propositional level (Lavandera, 1978), their interactional function and social meaning is variable depending on their syntactic configuration, intonational properties, speech activity, and, most importantly, their 
placement alongside other salient features within an individual's style. In summary, the indeterminate meaning of discourse features is resolved through in-the-moment stancetaking and the accretion of personal style across discourse.

A substantial challenge to the style-based explanation for the account presented here is the role of gender ideology. In the interactions analysed in section 3 , the knowledge being discussed and contested relates almost exclusively to sports. Sport is overwhelming dominated by men, illustrated by the extent to which many sports reward male participants with a higher profile and greater financial reward (Messner and Sabo, 1990; Scraton et al., 1999; Messner, 2007; McDonagh and Pappano, 2008). Instead of the meaning of the features analysed here being the product of a personal style, the differences could instead be explained as the result of participants reacting to ideological gender differences surrounding confidence about sporting knowledge. As women are materially and symbolically marginalised from sports, it is perhaps more likely for them to express such knowledge in a more reserved and mitigated fashion when compared to men, irrespective of their actual state of knowledge.

However, the framework of style is able to account for the ideological forces that frame these interactions. Eckert (2008) discusses how the stances taken in conversation can portray an individual in a particular way at that time, but that the resulting interactional persona (sports-expert and non-expert, in this case) is often associated with particular social or demographic categories. For example, in discussing 
sports, a more confident and assertive style may be ideologically linked with a male speaker, because in western society men are often expected to know more about sports than women. In this way, gender is inseparable from personal style. While styles involve an agentive subject creatively deploying stylistic resources, the resources they can access and some of the ways in which they can be used are not available to everybody in the same way (Bourdieu 1977). For example, Elle's use of I don't know and I think involves her selecting from the resources available to her in order to establish a particular interactional persona. At the same time, the range of meanings evoked through these forms is constrained by the fact that she is a woman talking about sports in light of a prevailing gender ideology that women know little about this area.

When situation-relevant knowledge is unequally distributed across individuals in the classroom, it heavily impacts upon the ways those individuals can use particular linguistic forms and restricts the type of stances that can be carried out. This unequal distribution of knowledge may be manifested in an individual's linguistic style, but that style is also framed and constrained by prevailing ideologies surrounding what is acceptable and appropriate for a particular subject. This phenomena occurs in all kinds of classrooms and, when combined with a mix of differing abilities and personalities, leads to different student personae emerging out of classroom discussion. Contextualising specific instances of stance-taking in terms of linguistic styles and the ideologies that frame them is a crucial element in moving towards a fuller 
understanding of why people say the things they do in all types of social interaction.

\section{Acknowledgements}

I would like to thank Emma Moore, Claire Nance, Gareth Walker and the anonymous reviewers, as well as audiences at Aston University, University of Edinburgh, University of Sheffield and University of Southampton for their helpful comments and feedback. This research was supported by a postgraduate studentship from the Arts \& Humanities Research Council.

\section{Transcription conventions}

[ ] Overlapping speech

[[ ]] Overlapping speech (double brackets used to distinguish an overlapping segment from a separate nearby overlap)

$=\quad$ No audible gap between turns

(.) Pause of 0.5 seconds or less

(xx) Inaudible speech (each $\mathrm{x}$ represents a single syllable)

(( )) Transcriber's comment

\{\} Non-lexical vocalisation (e.g. laughter)

\section{References}


Aijmer, K (1997) I think - an English modal particle. In: Swan, T and Westvik, OJ (eds) Modality in Germanic Languages: Historical and Comparative Perspectives. Berlin, Germany: Mouton de Gruyter, 1-47.

Allington, D and Swann, J (2009) Researching literary reading as social practice. Language and Literature 18(3): 219-230.

Ariel, M (2009) Discourse, grammar, discourse. Discourse Studies 11(1): 5-36.

Barth-Weingarten, D, Reber, E and Selting, M (eds) (2010) Prosody in Interaction. Amsterdam, The Netherlands: John Benjamins.

Benwell, B (1999) The collaborative construction of knowledge: issues, rhetorical and pedagogic discourse strategies in multidisciplinary tutorial discourse. Pragmatics 9(4): 535-565.

Benwell, B and Stokoe, E (2002) Constructing discussion tasks in university tutorials: shifting dynamics and identities. Discourse Studies 4(4): 429-453.

Bourdieu, P (1977) Outline of a Theory of Practice. Cambridge, U.K.: Cambridge University Press.

Bucholtz, M and Hall, K (2005) Identity and interaction: a sociocultural linguistics approach. Discourse Studies 7(4-5): 585-614.

Clift, R (2006) Indexing stance: reported speech as an interactional evidential. Journal of Sociolinguistics 10(5): 569-595. 
Couper-Kuhlen, E and Selting, M (eds) (1996) Prosody in Conversation. Cambridge, U.K.: Cambridge University Press.

Couper-Kuhlen, E and Ford, C (eds) (2004) Sound Patterns in Interaction: Crosslinguistic studies from conversation. Amsterdam, The Netherlands: John Benjamins.

Coupland, N (2007) Style: Language Variation and Identity. Cambridge, U.K.: Cambridge University Press.

Davies, B and Harré, R (1990) Positioning: the discursive production of selves. Journal for the Theory of Social Behaviour 20(1): 43-63.

Du Bois, J (2002) Stance and consequence. Paper presented at the $101^{\text {st }}$ Annual Meeting of the American Anthropological Association, New Orleans, USA, 20-24 November 2002.

Eckert, P (2001) Style and social meaning. In: Eckert, P and Rickford, JR (eds) Style and Sociolinguistic Variation. Cambridge, U.K.: Cambridge University Press, 119126.

Eckert, P (2008) Variation and the indexical field. Journal of Sociolinguistics 12(4): 453-476.

Eriksson Barajas, K and Aronsson, K (2009) Avid versus struggling readers: coconstrued pupil identities in school booktalk. Language and Literature 18(3): 281299. 
Fung, L and Carter, R (2007) Discourse markers and spoken English: native and learner use in pedagogic settings. Applied Linguistics 28(3): 410-439.

Gavins, J (2007) Text World Theory: An Introduction. Edinburgh, U.K.: Edinburgh University Press.

Goodwin, C and Heritage, J (1990) Conversation analysis. Annual Review of Anthropology 19: 283-307.

Hade, D (1991) Being literary in a literature-based classroom. Children's Literature in Education 22(1): 1-17.

Haegeman, P (1996) Business English in Flanders: A Study of Lingua Franca Telephone Interaction. PhD thesis, University of Ghent.

Hall, G (2008) Empirical research into the processing of free indirect discourse and the imperative of ecological validity. In: Zyngier, S, Bortolussi, M, Chesnokova, A and Auracher, J (eds) Directions in Empirical Literary Studies. Amsterdam: John Benjamins, 21-34.

Hall, G (2009) Texts, readers - and real readers. Language and Literature 18(3): 331337.

Heritage, J (1984) Garfinkel and Ethnomethodology. Cambridge, U.K.: Polity Press.

Holmes, J (1990) Hedges and boosters in women's and men's speech. Language and Communication 10(3): 185-205.

James, S (1994) [2005] Hoop Dreams. [DVD]. USA: The Criterion Collection. 
Jeffries, L (2008) The role of style in reader-involvement: deictic shifting in contemporary poems. Journal of Literary Semantics 37(1): 69-85.

Johnstone, B (2009) Stance, style, and the linguistic individual. In: Jaffe, A (ed.)

Stance: Sociolinguistic Perspectives. Oxford, U.K.: Oxford University Press, 29-

52.

Kärkkäinen, E (2003) Epistemic Stance in English Conversation: A Description of its Interactional Functions with a focus on I think. Amsterdam, The Netherlands: John Benjamins.

Kiesling, S (2001) Stances of whiteness and hegemony in fraternity men's discourse. Journal of Linguistic Anthropology 11(1): 101-115.

Kiesling, S (2009) Style as stance: stance as the explanation for patterns of sociolinguistic variation. In: Jaffe, A (ed.) Stance: Sociolinguistic Perspectives. Oxford: Blackwell, 171-194.

Kirkham, S (2009) Style and Discourse Variation: A Sociolinguistic Analysis of University Classroom Talk. MA thesis, University of Sheffield.

Kockelman, P (2004) Stance and subjectivity. Journal of Linguistic Anthropology 14(2): 127-150.

Lavandera, BR (1978) Where does the sociolinguistic variable stop? Language in Society 7(2): 171-182.

Local, J and Walker, G (2008) Stance and affect in conversation: on the interplay of 
sequential and phonetic resources. Text \& Talk 28(6): 723-747.

Longman, J (2001) The Girls of Summer: The U.S. Women's Soccer Team and How It Changed The World. New York, NY: HarperCollins.

McDonagh, E and Pappano, L (2008) Playing With The Boys: Why Separate is Not Equal in Sports. Oxford, U.K.: Oxford University Press.

Messner, MA and Sabo, DF (eds) (1990) Sport, Men and the Gender Order: Critical Feminist Perspectives. Champaign, IL: Human Kinetics Books.

Messner, MA (2007) Out of Play: Critical Essays on Gender and Sport. Albany, NY: State University of New York Press.

Moerman, M (1988) Talking Culture: Ethnography and Conversation Analysis. Philadelphia, PA: University of Pennsylvania Press.

Moore, E and Podesva, RJ (2009) Style, indexicality, and the social meaning of tag questions. Language in Society 38(4): 447-485.

Mondada, L (2007) Multimodal resources for turn-taking: pointing and the emergence of next possible speakers. Discourse Studies 9(2): 194-225.

Overstreet, M and Yule, G (2001) Formulaic disclaimers. Journal of Pragmatics 33(1): 45-60.

Pichler, H (2007) Form-function relations in discourse: the case of I DON'T KNOW. Newcastle Working Papers in Linguistics 13: 174-187.

Pichler, H (2008) A Qualitative-Quantitative Analysis of Negative Auxiliaries in a 
Northern English Dialect: I DON'T KNOW and I DON'T THINK, innit? PhD thesis, University of Aberdeen.

Rodman, D (1997) Bad as I Wanna Be. New York, NY: Dell Publishing.

Sacks, H, Schegloff, EA and Jefferson, G (1974) A simplest systematics for the organization of turn-taking in conversation. Language 50(4): 696-735.

Schegloff, EA (1993) Reflections on quantification in the study of conversation. Research on Language and Social Interaction 26: 99-128.

Scraton, S, Fasting, K, Pfister, G and Bunuel, A (1999) It's still a man's game?: the experiences of top-level European women footballers. International Review for the Sociology of Sport 34(2): 99-111.

Selting, M (2000) The construction of units in conversational talk. Language in Society 29(4): 477-517.

Stokoe, E (1995) Gender differences in undergraduates' talk: contrasting analyses, and what they offer. Feminism \& Psychology 5(1): 99-104.

Stokoe, E (1998) Talking about gender: the conversational construction of gender categories in academic discourse. Discourse \& Society 9(2): 217-240.

Stokoe, E (2000) Constructing topicality in university students' small-group discussion: a conversation analytic approach. Language and Education 14(3): 184-203.

Swann, J and Allington, D (2009) Reading groups and the language of literary texts: a case study in social reading. Language and Literature 18(3): 247-264. 
Wales, K (1996) Personal Pronouns in Present-Day English. Cambridge: Cambridge University Press.

Wilkinson, S and Kitzinger, C (2008) Using conversation analysis in feminist and critical research. Social and Personality Psychology Compass 2(2): 555-573.

Wortham, S (2008) The objectification of identity across events. Linguistics and Education 19(3): 294-311. 